\title{
O MITO ALENCARIANO
}

Eduardo Vieira Martins

Universidade Estadual de Londrina

U

ma leitura recorrente dos romances de José de Alencar, mais especificamente da trilogia indianista composta por $O$ guarani, Iracema e Ubirajara, interpreta-os como uma tentativa de recriar miticamente o passado nacional. Para mencionar apenas três estudos significativos que caminham nessa direção, vale recordar os trabalhos de Renato Ortiz, que analisa $O$ guarani como um "mito de fundação da brasilidade" (ORTIZ, 1988); de Valeria De Marco, que, a partir das distinções estabelecidas por Northrop Frye, compreende a mesma narrativa como uma "história romanesca que caminha para o mito" (MARCO, 1993); e de Alfredo Bosi, que, ao discutir a trajetória dos personagens de $O$ guarani e de Iracema, distingue um "mito sacrificial" que levaria o indígena a se submeter voluntariamente ao jugo do colonizador (BOSI, 1992).

A leitura do romance alencariano feita de uma perspectiva mítica coloca, como primeiro problema, a necessidade de se estabelecer o sentido atribuído a esse conceito, tarefa que, segundo Mircea Eliade, um dos principais estudiosos da matéria, não é nada simples, uma vez que, dada a multiplicidade de tipos e funções do mito, dificilmente poderíamos chegar a um denominador comum apto a unificá-los. Para Eliade, a definição "menos imperfeita" é a que o descreve como uma história sagrada que narra uma ação praticada por entes sobrenaturais num tempo primordial, dando origem a alguma coisa (o cosmo, uma ilha, um animal, uma planta, a morte etc) cuja existência é uma realidade passível de ser verificada ainda no momento da enunciação do mito (ELIADE, 1994, p. 11-2). Por narrar o surgimento de 
uma coisa real, o mito é compreendido pelas comunidades que o criam como uma história verdadeira. No caso dos mitos de origem, interpretados pelo pesquisador como um prolongamento da cosmogonia, teríamos a narração de como algo que não existia no momento da criação do mundo passou a existir: "Os mitos de origem prolongam e completam o mito cosmogônico: eles contam como o Mundo foi modificado, enriquecido ou empobrecido" (ELIADE, 1994, p. 25-5). Nesse sentido, compreender $O$ guarani como um mito de origem do Brasil equivale a interpretá-lo como narração do surgimento do país em decorrência de uma ação grandiosa, realizada num passado distante, como fez Renato Ortiz no ensaio mencionado anteriormente. Os mitos de fundação, diz ele, transcorrem

num passado longínquo que serve de modelo para a reprodução da sociedade atual. Isto significa que o mito 'para' a história se situa aquém dela, e, ao descrever um estado anterior, legitima a continuidade do presente. [...] O guarani partilha desta dimensão mítica, e o autor anuncia, logo no início do livro, que a estória se passa num período em que 'civilização não tivera tempo de penetrar o interior', isto é, quando o Brasil se encontrava ainda na sua virgindade originária e a terra não havia sido profanada pela irreversibilidade do tempo. (ORTIZ, 1988, p. 262)

Outra definição do mito, agora de uma perspectiva dos estudos literários, pode ser encontrada na Anatomia da crítica, de Northrop Frye, livro que forneceu a moldura para a análise do romance alencariano feita por Valeria De Marco em A perda das ilusões. Num primeiro momento, ao desenvolver o que denomina de "teoria dos modos", Frye, partindo da consideração aristotélica das “diferentes posições das personagens”, que podem ser melhores, piores ou semelhantes a nós, considera o mito como uma história na qual o "herói é um ser divino", "superior em condição tanto aos homens como ao meio desses homens" (FRYE, s/d, p. 39). Posteriormente, em outro ensaio do mesmo livro, aprofunda a questão do mito, definido como um tipo de narrativa que abandona a perspectiva realista e coloca em cena personagens superiores aos homens comuns - os deuses - que operam ações impossiveis de ocorrerem no nosso mundo, ações como as que só acontecem nas histórias. Dessa perspectiva, o mundo mítico é "um mundo abstra- 
to ou puramente literário de delineamento ficcional ou temático, não afetado pelos cânones da adaptação plausível à experiência comum. Em termos de narração, o mito é a imitação das ações que raiam pelos limites concebíveis do desejo, ou que se situam nesses limites" (FRYE, s/d, p. 138). Se pensarmos nas categorias de Frye, os romances indianistas de Alencar, cujos personagens não são deuses, mas um herói "superior em grau aos outros homens e seu meio" (FRYE, s/d, p. 39), não são mitos no sentido estrito do termo, e sim, como propõe Valeria De Marco na sua leitura de $O$ guarani, uma "estória romanesca que caminha para o mito" (MARCO, 1993, p. 17).

Dada a multiplicidade de definições do mito, parece produtivo procurar identificar a visão que o próprio Alencar tinha sobre a questão, para, a partir dela, depreender os procedimentos retóricos empregados pelo autor para dotar suas narrativas de uma dimensão mítica. O problema do mito foi discutido pelo romancista em dois momentos precisos da sua reflexão teórica: primeiramente, de forma quase que acidental, em 1857, ao criticar $A$ confederação dos tamoios, de Gonçalves de Magalhães; e, num segundo momento, de forma mais detida, em 1874, em $O$ nosso cancioneiro, um conjunto de cartas sobre as cantigas populares dos vaqueiros cearenses. Se considerarmos os contextos em que o problema do mito se insere, veremos que, em ambos os casos, a questão surge relacionada à discussão do gênero épico.

Estimulado pelo espírito nacionalista que se seguiu à Independência, o romantismo brasileiro demonstrou grande interesse pela epopéia, percebida como a forma mais adequada para a composição de uma obra em louvor ao jovem país: "O ideal dessas gerações", diz Antonio Candido, "era transcender a poesia lírica pela elaboração de uma grande epopéia nacional, preferivelmente de assunto indígena" (CANDIDO, 1987, p. 347). Gonçalves de Magalhães, valido de Dom Pedro II e um dos principais expoentes do grupo introdutor do romantismo no Brasil, tomou a si a tarefa e apresentou $A$ confederação dos tamoios como a epopéia nacional ansiosamente esperada pelos homens de letras do período. Para Alencar, entretanto, o poema não logrou seus objetivos, não pela escolha do tema indígena, que lhe parecia conveniente, mas porque o autor não soube elevar a matéria e os personagens ao nível de grandiosidade adequado, rompendo, assim, o decoro da obra. Inserindo o poema de Magalhães na tradição ocidental, o crítico asseverava que os grandes modelos do gênero "são mitos ou idéias poetizadas 
que preludiam o nascimento de uma nova religião, de uma civilização, de uma nova língua, ou mesmo de uma nova literatura"; ou ainda, "são apenas obras de arte, criações literárias feitas sobre um fato histórico, sobre uma ficção religiosa, sobre uma idéia grande ou sobre as tradições nacionais de um povo" (ALENCAR, 1953, p. 61). Nesse primeiro momento de sua reflexão, Alencar compreende o mito, associado ao épico, como a narração grandiosa da origem de uma instituição importante, como uma religião, uma civilização, ou, num nível mais modesto, mas não menos válido para nossa discussão, das "tradições nacionais de um povo".

Foi apenas muitos anos depois de ter feito essas considerações que Alencar retomou a questão do mito ao discutir a poesia popular dos vaqueiros cearenses. Segundo ele, as cantigas entoadas no interior de sua província natal se enquadravam no "gênero pastoril", como era de se esperar que acontecesse numa região dominada pela pecuária. Contudo, ao contrário do que ocorria com a poesia dos pastores europeus, que assumia a forma mais serena do "idílio", o cancioneiro popular cearense tinha "cunho épico", tonalidade que lhe era imposta pelas duras condições da vida do sertão, que convertiam a atividade do vaqueiro numa "luta constante" (ALENCAR, 1960, p. 962-63).

A par dessa dimensão épica, o que diferenciava as cantigas sertanejas era o papel desempenhado pelo boi em algumas delas. Analisando o Rabicho da Geralda, que narra as peripécias do boi de mesmo nome, afirma:

Nem vestígios se encontram de alegoria nessas rapsódias; o boi figura por si, tem uma individualidade própria. Daí o cunho mitológico desses heróis sertanejos.

$\mathrm{Na}$ infância dos povos, certas individualidades mais pujantes absorvem em si a tradição de fatos praticados por indivíduos cujo nome se perde; e tornam-se por esse modo símbolo de uma idéia ou de uma época.

Com o incremento da civilização, que nivela os homens, debilita-se aquela tendência; e o mitologismo só aparece naquelas latitudes sociais onde ainda não dissiparam-se de todo a primitiva rudeza e ingenuidade do povo. Estou convencido de que os heróis das lendas sertanejas são mitos, e resumem o entusiasmo do vaqueiro pela raça generosa, companheira inseparável de suas fadigas, e próvida mãe que o alimenta e veste.

O caráter poético das nossas rapsódias pastoris não é comum a outros países. (ALENCAR, 1960, p. 978, grifo meu) 
A passagem é importantíssima, pois explicita a visão alencariana do mito como um ser que, ao concentrar em si a tradição de feitos grandiosos praticados por indivíduos cujos nomes foram esquecidos, reveste-se de uma dimensão simbólica, tornando-se o representante das virtudes mais caras de uma comunidade. Nesse sentido, conferir estatura mítica a personagens, episódios e cenários equivale a transformá-los nessas "individualidades mais pujantes”, que simbolizam uma idéia ou uma época. Como fazê-lo, entretanto? Como obter, num poema ou num romance, esse efeito de mitificação? $\mathrm{Na}$ leitura que faz do cancioneiro cearense, Alencar identifica dois ornatos empregados pelos vates do sertão para mitificar seus heróis: a hipérbole e a amplificação, ambos previstos nos manuais de retórica e poética que se encontravam em circulação no Brasil do século XIX.

Segundo Hugh Blair, autor escocês das Lectures on rhetoric and belles lettres, um compêndio amplamente divulgado e imitado no Brasil, a hipérbole é uma figura que "consiste em exagerar um objeto além dos seus limites naturais” (BLAIR, 1829, p. 169). Desenvolvendo a análise, o Pe. Lopes Gama, autor das Lições elementares de eloqüência nacional, afirma:

Quando estamos vivamente penetrados duma idéia, e os termos comuns nos parecem apoucados para levantar o espírito até a expressão correspondente, nos servimos de palavras, que literalmente tomadas passam além da verdade, e representam mais, ou menos para significar algum excesso, assim no grande como no pequeno. O ouvinte rebaixa da expressão hiperbólica o que é mister rebaixar, formando uma imagem mais conforme a nossa, do que a que poderíamos excitar-lhe com as palavras próprias. (GAMA, 1846, p. 156-57)

De forma semelhante à proposta por Lopes Gama, Alencar observa a certa altura da sua polêmica com Joaquim Nabuco que esse ornato "faz sobressair pelo contraste a magnitude do objeto" (COUTINHO, 1978, p. 178). Em $O$ nosso cancioneiro, ao analisar a cantiga popular do Boi Espácio, considera que "a hipérbole, ultrapassando todas as raias do verossímil, atesta a admiração que devia ter inspirado o herói” (ALENCAR, 1960, p. 971). Movido por essa admiração, o vate sertanejo exagera as qualidades do animal por meio da hipérbole, compreendida por Alencar como um recurso capaz de fixar 
a paixão despertada no poeta pelo objeto do seu canto e de transmiti-la ao destinatário. Sua importância e eficácia, portanto, reside na capacidade de mover as paixões, mesmo que, para isso, tenha que se afastar da verdade objetiva: num fragmento da cantiga destacado como exemplo de hipérbole ou exageração, o poeta afirma que de um chifre do boi Espácio "fez-se uma canoa/ Para se passar a gente/ Que viesse de Lisboa” (ALENCAR, 1960, p. 971).

Quanto à amplificação, o segundo dispositivo retórico apontado por Alencar como capaz de produzir o efeito de mitificação, Hugh Blair considera que ela não é propriamente uma figura, mas uma forma de organizar os ornamentos do discurso de maneira a produzir o aumento ou a diminuição da(s) qualidade(s) que o orador deseja ressaltar ou atenuar. Segundo Francisco Freire de Carvalho, outro retor bastante lido no período, a amplificação é um tipo de conceito que "serve para engrandecer ou apoucar os objetos”. Haveria, segundo ele, duas maneiras de se obter esse efeito: a amplificação absoluta, na qual o objeto é considerado "em si mesmo"; e a relativa, que "sai fora do objeto, e comparando-o com outro de uma ordem inferior, igual ou superior, consegue avultá-lo muito mais do que antes se afigurava” (CARVALHO, 1880, p. 105-06).

Ao contrário do que ocorria com a hipérbole, Alencar não utiliza o termo "amplificação" em $O$ nosso cancioneiro; contudo, mesmo sem a nomear, aponta sua utilização no Rabicho da Geralda, cantiga que, como o Boi Espácio, também narra as proezas de um boi. Prosseguindo a análise da feição assumida pelo animal, Alencar afirma que, diferentemente do que ocorre na poesia européia, na qual os bichos surgem como "sócio[s]" ou “servo[s]” do homem, no cancioneiro cearense o boi é o próprio herói, o objeto da celebração: "Aí está o toque de magnanimidade dos rústicos vates do sertão. Homero engrandece os guerreiros troianos para realçar o valor dos gregos. Os nossos rapsodos, imitando, sem o saberem, ao criador da epopéia, exaltam o homem para glorificar o animal” (ALENCAR, 1960, p. 978). O dispositivo consiste em contrapor o objeto que se pretende amplificar (os guerreiros gregos, no caso de Homero, ou o boi, no caso dos sertanejos) a outro objeto que, em si, já apresenta em alto grau a qualidade exaltada (a bravura dos troianos, no primeiro caso, ou dos vaqueiros, no segundo); a seguir, o poeta mostra que o objeto do seu canto supera esse comparante em grandeza, amplificando, assim, o seu valor: o vaqueiro cearense é des- 
crito como forte, destemido e grandioso, mas quando o boi entra em cena e o derrota demonstra possuir as mesmas virtudes em grau mais elevado.

Ainda que as reflexões desenvolvidas por Alencar em $O$ nosso cancioneiro sejam posteriores à redação de $O$ guarani, primeiro painel do tríptico indianista, o romance de 1857 ilustra claramente a idéia do mito como narrativa da origem de algo grandioso ou como ser superior que representa uma idéia, além de deixar perceber a utilização da hipérbole e da amplificação como recursos aptos a mitificar personagens e episódios. Para não alongar excessivamente a exposição, veremos como os dois ornamentos são empregados na construção de Peri, herói indígena do drama do Paquequer.

Em $O$ guarani, a gênese da nova civilização surge como fruto do encontro de portugueses e indígenas em meio à floresta quase intocada. Nesse cenário privilegiado, na aurora de um novo tempo, Alencar introduziu, como ancestrais míticos do brasileiro, o que de mais elevado conseguiu vislumbrar no nosso passado. No tronco português, escolheu uma família de nobres de solar e brasão, engrandecida pelos títulos e feitos de seus fidalgos. Ceci, oriunda dessa família, tem suas qualidades aguçadas pelo fato de ter nascido e crescido em contato com a natureza americana. No tronco indígena, o romancista imaginou um chefe goitacá que reúne em si não apenas as qualidades físicas aptas a fazerem dele um herói invencível na guerra, como também a inteligência e os bons sentimentos que o transformam num verdadeiro rei das florestas americanas, um homólogo selvagem do nobre português. Para dotá-lo de dimensão mítica, o narrador utiliza largamente a amplificação e a hipérbole.

A primeira pode ser percebida nas inúmeras comparações utilizadas para delinear o perfil do indígena, construído, em grande medida, por oposição a outros personagens. Guerreiro valoroso, chefe da nação Goitacá, Peri abandona sua tribo e vem voluntariamente colocar-se a serviço de Dom Antonio de Mariz quando descobre que sua mãe havia sido salva pelo fidalgo. Como o português, Peri também é nobre: se não possui a nobreza de brasão, tem uma nobreza natural, talvez mais verdadeira e profunda do que a firmada em títulos e distinções: "Enquanto falava, um assomo de orgulho selvagem da força e da coragem lhe brilhava nos olhos negros e dava certa nobreza ao seu gesto. Embora ignorante, filho das florestas, era um rei; tinha a realeza da força" (ALENCAR, 1999, p. 189). 
Para amplificar o valor do chefe goitacá, o narrador compara suas qualidades com as de outros personagens, afirmando sempre a sua superioridade. Assim, depois de louvar a grande destreza de Álvaro de Sá no manuseio das armas, afirma que o cavalheiro "sabia que só um homem podia lutar com ele e levar-lhe vantagem em qualquer arma, e esse era Peri [...]" (ALENCAR, 1999, p. 25). Seu combate contra Aires Gomes, narrado de perspectiva cômica, é apresentado como "duelo original e curioso [...] em que as armas lutavam contra a agilidade, e o ferro contra um vime delgado" (ALENCAR, 1999, p. 227). A amplificação é aprofundada na série de comparações entre o chefe goitacá e os índios aimorés, inimigos de Dom Antonio de Mariz. Na descrição desses índios, o narrador mobiliza todo o arsenal da bestialidade para rebaixá-los a uma condição subumana: seus cabelos cobrem a fronte, "criada por Deus para a sede da inteligência"; seus dentes são pontiagudos como os do jaguar. em vez de lábios, têm "mandíbulas de fera"; no lugar de unhas, "garras temíveis" (ALENCAR, 1999, p. 388). Ao defender o solar de Dom Antônio de Mariz, Peri entra em confronto com os aimorés e os derrota. Em contraste com eles, seja na sua caracterização física e psicológica, seja na narração dos seus atos, tem engrandecidas suas qualidades guerreiras, intelectuais e morais. Mas o aspecto mais interessante da amplificação colocada a serviço da construção de Peri é a narração do mito de Tamandaré, descrito por Alencar numa nota como o "Noé indígena” (ALENCAR, 1999, p. 542), pela qual o herói do romance atualiza as tradições cristã e indígena, alçando-se ao nível de grandeza dos seus protagonistas. Como observa Valeria De Marco, a descrição da enchente do rio Paquequer reproduz elementos do mito narrado por Peri, mito que, por sua vez, irá lhe fornecer um exemplo de ação que poderá salvar a vida de Ceci (MARCO, 1993, p. 87).

O processo de mitificação de Peri se completa com o uso da hipérbole, por meio da qual são descritas qualidades e narrados episódios que rompem por completo os limites do mundo real. Peri luta com uma onça, desce a uma gruta cheia de serpentes venenosas para recuperar um bracelete de Ceci, enfrenta sozinho uma tribo de aimorés, bebe veneno como estratégia para exterminar os inimigos e depois se cura, salva sua senhora em meio a um cerco impossível de ser rompido e, por fim, proeza das proezas, arranca uma palmeira do chão para salvar a menina da enchente que os ameaçava. 
Episódios como esses foram censurados por inúmeros críticos que acusavam o romancista de falsear a realidade. Joaquim Nabuco expressou de forma sucinta essa postura: "Não poderia eu, sem escrever um livro tão grande como o Guarani, notar tudo o que nele parece-me ofender a história, a verdade, a arte, e as leis da composição literária" (COUTINHO, 1978, p. 86). Partindo do pressuposto de que o romance deveria manter-se nos limites do mundo extraliterário, esse tipo de crítica tacha de falso tudo o que se afasta do dado observável. Em Alencar entretanto, a par do desejo de ancorar o romance na história, verifica-se uma tendência igualmente poderosa de transfigurar a realidade através da imaginação, elevando-a a um patamar superior de perfeição e grandiosidade. Defendendo-se dos críticos que o acusavam de imitar Fenimore Cooper, declarou:

Cooper considera o indígena sob o ponto de vista social, e na descrição dos seus costumes foi realista; apresentou-o sob o aspecto vulgar.

N'O guarani o selvagem é um ideal, que o escritor intenta poetizar, despindo-o da crosta grosseira de que o envolveram os cronistas, e arrancando-o ao ridículo que sobre ele projetam os restos embrutecidos da quase extinta raça. (ALENCAR, 1990, p. 86)

Ao contrário da perspectiva realista, que tentaria retratar fielmente o selvagem, o olhar de Alencar assume um ponto de vista poético-idealizante, pois só assim poderia dotar sua matéria de dimensão simbólica e criar um mito de fundação para o país recém-independente. Nesse movimento, muitas vezes as amarras que prendem a narrativa ao solo do real se rompem e a imaginação atinge o nível do sonho e do desejo, onde desliza a palmeira levando Peri e Ceci, casal original, em direção ao nascimento de um novo povo. Se muitos críticos não o compreenderam, compreendeu-o um poeta, Cruz e Souza, que lhe dedicou o seguinte soneto:

\section{O Final do Guarani}

Ceci - é a virgem loira das brancas harmonias, a doce-flor-azul dos sonhos cor de rosa, Peri - o índio ousado das bruscas fantasias, o tigre dos sertões - de alma luminosa. 
Amam-se com amor indômito e latente

que nunca foi traçado nem pode ser descrito.

Com este amor selvagem que anda no infinito.

E brinca nos juncais, - ao lado da serpente.

Porém... no lance extremo, o lance pavoroso, assim por entre a morte e os tons de um puro gozo, dos leques da palmeira à nota musical...

Vão ambos a sorrir, às águas arrojados, mansos como a luz, tranqüilos, enlaçados e perdem-se na noite serena do ideal!... (SOUZA, 1961, p. 230)

\section{BIBLIOGRAFIA}

ALENCAR, José de. Cartas sobre "A confederação dos tamoios". In: CASTELLO, José Aderaldo. A polêmica sobre “A confederação dos tamoios". SP: FFCL/USP, 1953. Como e porque sou romancista. Campinas: Pontes, 1990. O guarani. SP: Ateliê, 1999. O nosso cancioneiro. In: Obra completa. RJ: Aguilar, 1960.

BLAIR, Hugh. Lectures on rhetoric and belles lettres. Philadelphia: James Kay, Jun. and Brother, 1829.

CANDIDO, Antonio. “A literatura durante o império”. In: HOLANDA, Sérgio Buarque. HGCB. RJ: Difel, 1987, t. II, v. 3.

CARVALHO, Francisco Freire de. Lições elementares de eloqüência nacional. Lisboa: Rolland e Semiond, 1880.

COUTINHO, Afrânio (org.). A polêmica Alencar-Nabuco. RJ: Tempo Brasileiro, 1978.

ELIADE, Mircea. Mito e realidade. SP: Perspectiva, 1994.

FRYE, Northrop. Anatomia da crítica. SP: Cutrix, s/d.

GAMA, Miguel do Sacramento Lopes. Lições de eloqüência nacional. RJ: Tip. Imparcial de Paula Brito, 1846.

ORTIZ, Renato. "O guarani: um mito de fundação da brasilidade”. In: Ciência e cultura, n.o 40, março 1988.

SOUZA, Cruz e. Obra completa. RJ: Aguilar, 1961. 